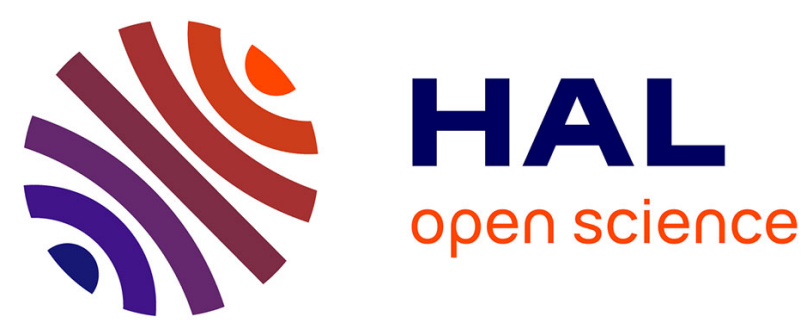

\title{
In situ and time-resolved infrared detection of the reactivity induced by electrons in polymer films
}

Michael Bouhier, G. Vigneron, Y Ngono-Ravache, S P Shirdhonkar, Jean-Philippe Renault, S P Le Caër

\section{- To cite this version:}

Michael Bouhier, G. Vigneron, Y Ngono-Ravache, S P Shirdhonkar, Jean-Philippe Renault, et al.. In situ and time-resolved infrared detection of the reactivity induced by electrons in polymer films. Review of Scientific Instruments, 2017, 88, pp.34102. 10.1063/1.4978442 cea-01493350

\section{HAL Id: cea-01493350 https://hal-cea.archives-ouvertes.fr/cea-01493350}

Submitted on 21 Mar 2017

HAL is a multi-disciplinary open access archive for the deposit and dissemination of scientific research documents, whether they are published or not. The documents may come from teaching and research institutions in France or abroad, or from public or private research centers.
L'archive ouverte pluridisciplinaire HAL, est destinée au dépôt et à la diffusion de documents scientifiques de niveau recherche, publiés ou non, émanant des établissements d'enseignement et de recherche français ou étrangers, des laboratoires publics ou privés. 
In situ and time-resolved infrared detection of the reactivity induced by electrons in polymer films

M. Bouhier, G. Vigneron, Y. Ngono-Ravache, M. Shirdhonkar, J. P. Renault, and S. Le Caër

Citation: Review of Scientific Instruments 88, 034102 (2017); doi: 10.1063/1.4978442

View online: http://dx.doi.org/10.1063/1.4978442

View Table of Contents: http://aip.scitation.org/toc/rsi/88/3

Published by the American Institute of Physics 


\title{
In situ and time-resolved infrared detection of the reactivity induced by electrons in polymer films
}

\author{
M. Bouhier, ${ }^{1}$ G. Vigneron, ${ }^{1}$ Y. Ngono-Ravache, ${ }^{2}$ M. Shirdhonkar, ${ }^{1}$ J. P. Renault, ${ }^{1}$ \\ and S. Le Caër ${ }^{1, a)}$ \\ ${ }^{1}$ LIONS, NIMBE, UMR 3685, CEA, CNRS, Université Paris Saclay, F-91191 Gif-sur-Yvette Cedex, France \\ ${ }^{2}$ DRF/IRAMIS/CIMAP, UMR 6252, BP 5133, F-14070 Caen Cedex 5, France
}

(Received 16 November 2016; accepted 27 February 2017; published online 17 March 2017)

\begin{abstract}
The real time and in situ analysis of chemical reactions such as polymerization reactions, polymer degradation, and oxidation of polymers is of utmost importance. Surprisingly, only few experimental tools allowing this are available. To bridge this gap, we have developed a new experimental setup coupling a $60 \mathrm{keV}$ electron gun with an infrared spectrometer operating in the mid-IR region $\left(800-4000 \mathrm{~cm}^{-1}\right)$ and associated with the rapid scan mode. The measurements are performed using the infrared reflection absorption spectroscopy approach. We worked here with $0.5-25 \mathrm{~ms}$ pulses for which the dose per pulse ranges from 4 to $200 \mathrm{kGy}$. Combining pulse electrons with rapid scan analysis enables performing experiments with a time resolution of $80 \mathrm{~ms}$ (and above). Therefore, this new platform can, for instance, give direct insights into reaction mechanisms at stake during the degradation of polymers. First results on a bisphenol A polycarbonate irradiated under vacuum enabling the validation of this new setup and also the recording of time-resolved spectra are presented. Reaction mechanisms are then proposed. Published by AIP Publishing. [http://dx.doi.org/10.1063/1.4978442]
\end{abstract}

\section{INTRODUCTION}

Infrared (IR) spectroscopy is a very powerful technique for organic compound characterization and quantification, and it has been used for the study of polymer modification for a long time. Moreover, time resolved infrared spectroscopy enables identifying the transient species created by an excitation (laser... .). ${ }^{1}$ Indeed, IR spectroscopy provides a direct insight into the chemical bonds that have been modified, at the opposite of UV-visible spectroscopy that gives broad and featureless bands that can be difficult to assign. Moreover, the IR spectra measured are directly comparable to the ones obtained by calculations, whereas these calculations are much more difficult in the case of UV-visible spectroscopy. In spite of all these advantages, it is scarcely coupled to accelerated electron sources, although it is a precious tool to identify species and determine reaction mechanisms, for example, during the degradation of polymers.

The first in situ coupling of infrared detection with accelerated particles arose from astrophysics/astrochemistry: studies were undertaken in the 1980s to understand the differences between new and evolved comets. ${ }^{2,3}$ Then, the in situ coupling of swift heavy ions with infrared spectroscopy was performed in the 1990s to understand the behavior of polymers under irradiation. ${ }^{4,5}$ Nevertheless, these experiments were static ones: no time resolution was achieved. The first in situ kinetics measured by coupling a linear accelerator with infrared spectroscopy was obtained by Mascioni et al. who studied the radiation induced cationic polymerization of epoxy systems, but this study was only possible in the near infrared spectral range. ${ }^{6}$ The first coupling of accelerated electrons with a time-resolved

\footnotetext{
a) Author to whom correspondence should be addressed. Electronic mail: sophie.le-caer@cea.fr
}

infrared detection (Fourier Transform infrared spectrometer) using the mid infrared spectral range was reported ten years ago, ${ }^{7,8}$ with a time resolution of $24 \mathrm{~s}$. Nevertheless, this experimental setup had a large optical path $(6 \mathrm{~m})$ which caused some trouble due to the presence of residual water molecules. Since then, the Brookhaven National Laboratory (BNL) has developed a nanosecond time-resolved infrared detection coupled to the picosecond pulse radiolysis facility LEAF. ${ }^{9-11}$ In this setup, infrared radiation is provided thanks to externalcavity quantum cascade infrared lasers. They are compact and each provides infrared radiation in a $100-200 \mathrm{~cm}^{-1}$ range. ${ }^{11}$ The Brookhaven National Laboratory possesses twelve of these quantum cascade lasers covering the $1050-2300 \mathrm{~cm}^{-1}$ wavenumber range. ${ }^{11}$

We have decided to build a setup dedicated to the determination of reaction mechanisms using time-resolved infrared spectroscopy in the mid-IR region. It is complementary to the setup at BNL in terms of probed IR region $\left(800-4000 \mathrm{~cm}^{-1}\right.$ in the present work) and time resolution of the electron gun (microsecond time resolution here). Moreover, to mitigate the trouble coming from residual water molecules on the optical path, we designed a compact setup. For these reasons, we use a $60 \mathrm{keV}$ pulsed electron gun (minimum pulse duration: $2 \mu \mathrm{s})$ enabling time-resolved experiments. The maximum penetration depth of the extracted electrons is around $50 \mu \mathrm{m}$ in most of the polymers and sets the thickness of the polymers that can be studied with this setup. As for IR analyses, we use an IR beam arising from a commercial infrared spectrometer and the $800-4000 \mathrm{~cm}^{-1}$ spectral region. The measurements are performed using the InfraRed Reflection Absorption Spectroscopy (IRRAS) approach. The aim of this paper is to present this new experimental platform and the first results obtained on bisphenol A polycarbonate films irradiated under vacuum with a time resolution of 
$80 \mathrm{~ms}$, which gives insights into the reaction mechanisms at stake during the degradation of polymers. More generally, it provides information on the reactivity induced by ionizing radiation.

\section{THE EXPERIMENTAL SETUP}

\section{A. The ACCIR (accelerator coupled to infrared spectroscopy) platform}

\section{The electron gun}

The EGH-6210 $60 \mathrm{keV}$ electron gun was purchased from Kimball Physics. The gun uses a single-crystal $\mathrm{LaB}_{6}$ cathode to produce an intermediate energy and high current focusable electron beam, allowing irradiations at high doses in a reduced number of pulses. The energy beam is adjustable from 1 to $60 \mathrm{keV}$. In the present study, the energy was set to the highest available energy $(60 \mathrm{keV})$ which enables the electrons to penetrate in typical organic samples on a thickness of about $50 \mu \mathrm{m}$ according to simulations performed with the ESTAR database. ${ }^{12}$ This penetration depth is of the same order of magnitude as the optical paths in infrared spectroscopy.

The electron beam size and position can be tuned thanks to a magnetic lens and an $x-y$ deflection system. The source voltage is set at $2.6 \mathrm{~V}$ (typically between 2 and $3 \mathrm{~V}$, with a current between 1 and $3 \mathrm{~A}$ ) and the grid voltage of the electronic shutter is set around $300 \mathrm{~V}$. The electron beam is totally blocked over a threshold voltage (cutoff value) around $500 \mathrm{~V}$ which depends on the source voltage. Hence, the electron beam can be pulsed by setting the grid voltage over or below this cutoff value. The grid voltage is set thanks to a transistor-transistor logic (TTL) signal sent to the grid control board by a pulse generator Keithley 3390.

Once these parameters are set, the dose on the sample can be tuned by adjusting the pulse duration. The pulse duration can vary from $2 \mu$ s to DC with a maximum $5 \mathrm{kHz}$ repetition rate and a minimum $500 \mathrm{~ns}$ rise/fall time (see Fig. S1 in the supplementary material with an example). At a given pulse duration, the dose can also be tuned by changing the grid voltage.
A home-made Python program controls the parameters of the generator and triggers the electron pulses at a given duration and at a given frequency ( $2 \mathrm{~Hz}$ here). In the present work, electron gun parameters have been set to a $2.6 \mathrm{~V}$ source voltage with a grid value of $330 \mathrm{~V}$. Pulse durations were 0.5 and $25 \mathrm{~ms}$. This latter case allows delivering a high dose to the sample, which is necessary for rapid-scan measurements giving access to time-resolved experiments in the $80 \mathrm{~ms}$ - seconds, and even minute time range.

All the different parameters are given in Fig. 1. A general picture of the ACCIR platform can be seen in Fig. 2.

\section{The experimental chamber with the samples}

The gun is operated in vacuum $\left(5 \times 10^{-8}\right.$ bar $)$. A differential pumping system ensures the injection of this vacuumgenerated electron beam into the experimental chamber containing the sample and maintained at $7 \times 10^{-7}$ bar. The irradiation chamber has an internal diameter of $25 \mathrm{~cm}$ and a length of $40 \mathrm{~cm}$. This compact chamber has a small volume that enables a rapid pumping. The electron gun and the experimental chamber are isolated from each other thanks to a pneumatic gate valve (Fig. 1). We worked here with a spot diameter of roughly $6 \mathrm{~mm}$, which ensures an electron beam larger than the probe infrared beam (see below and Fig. 4). Moreover, the electron beam diameter is smaller than the orifice diameter (internal diameter: $40 \mathrm{~mm}$ ) between the electron gun and the irradiation chamber. Therefore all electrons are transferred towards the sample. The value of the orifice diameter assures also a good quality of vacuum for the electron gun when the valve is open.

In the irradiation chamber, the sample holder is motorized and can be moved in the $x, y$ directions (area $25 \times 25 \mathrm{~mm}^{2}$ ) to enable the electron beam to strike different positions and hence, different samples on the sample holder. The sample holder possesses different irradiation positions. On several regions of the sample holder, there are the following:

- a hole that enables the electron beam to pass through and then to be collected on the Faraday cup designed for dosimetry;

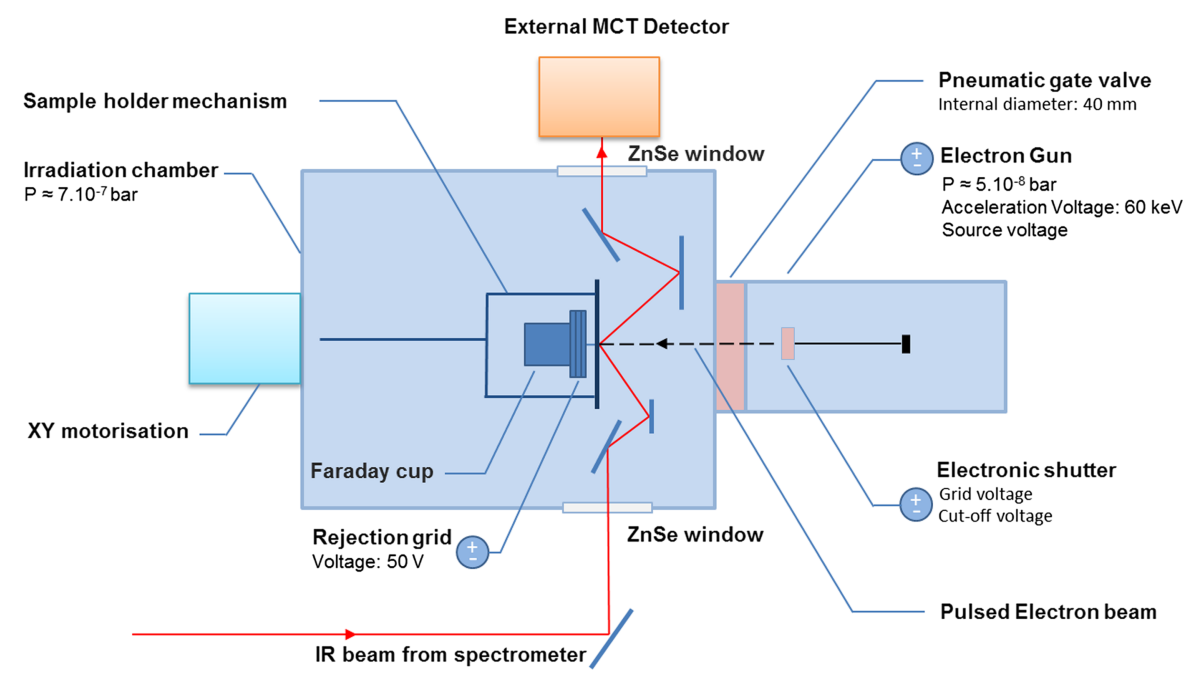

FIG. 1. Schematic illustration of the electron gun (right) connected to the irradiation chamber. The optical path of the infrared beam is also given. Let us point out that the MCT detector is installed on the irradiation chamber. 


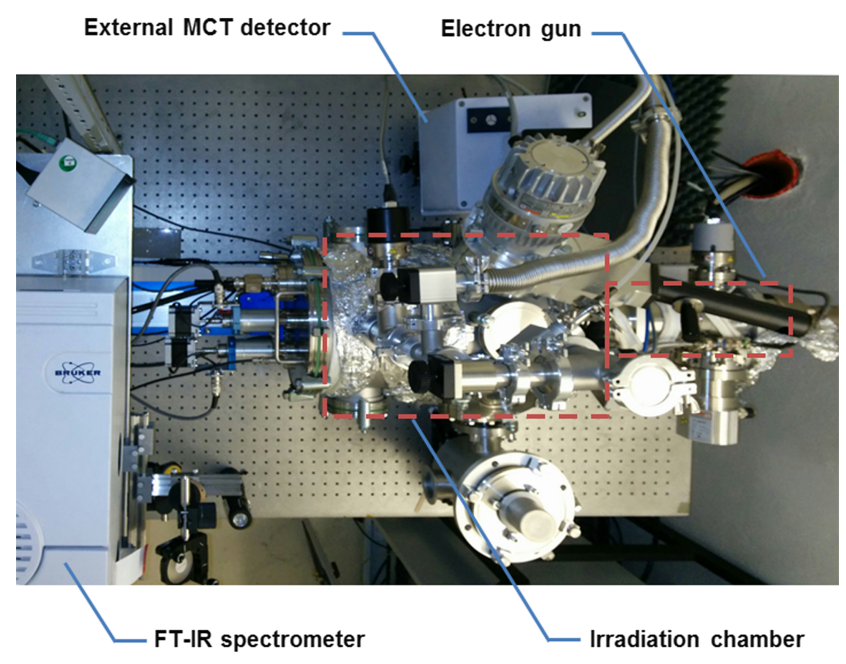

FIG. 2. Top photo of the experimental ACCIR setup.

- a $\mathrm{KBr}$ pellet to record the background spectrum;

- a Gafchromic HD-810 film that enables to visualize the size and the shape of the electron beam. It has a surface layer of $0.75 \mu \mathrm{m}$ and an active layer of $6.5 \mu \mathrm{m} .{ }^{13}$ Hence, the $60 \mathrm{keV}$ electrons will penetrate into the entire surface and active layers. When the film is exposed to irradiation, a blue colored polymer is formed with absorption maxima at about $610 \mathrm{~nm}$ and $670 \mathrm{~nm} ;{ }^{14}$

- chromium doped alumina obtained from Saint Gobain Solcera to visualize the electron beam directly by phosphorescence (see below); ${ }^{15}$

- the sample under study.

An issue in performing irradiation experiments lies in the heating of the sample. Few systems measuring temperature are able to withstand radiation. In the present case, we chose to monitor the sample temperature with a glass encapsulated NTC thermistor (GAG10K3976B1 from TE Connectivity). This sensor can detect temperatures from $-40{ }^{\circ} \mathrm{C}$ up to $250{ }^{\circ} \mathrm{C}$ with an accuracy of $\pm 0.1^{\circ} \mathrm{C}$ and a typical time constant of 500 $\mathrm{ms}$. The sensor is installed in front of the sample (Fig. 5). Measurements are performed at a frequency of $20 \mathrm{~Hz}$. The sample temperature was followed for different pulse durations, representative of the experimental conditions under which infrared spectra are recorded (Fig. 3). Fig. 3(a) corresponds to the experimental conditions of rapid scan measurements. In this case, the temperature increase detected is less than $0.5^{\circ} \mathrm{C}$, which is considered as negligible. Fig. 3(b) corresponds to the worst conditions under which static infrared spectra were recorded. In that case, the temperature increase is about $5{ }^{\circ} \mathrm{C}$. Nevertheless, temperature returns to its initial value quickly after the end of irradiation. Roughly $20 \mathrm{~s}$ after irradiation has been stopped, the temperature increase is only about $1{ }^{\circ} \mathrm{C}$. Hence, under the present conditions, the modifications observed in the materials are solely related to irradiation (and not thermal ones).

The Gafchromic film was used to measure precisely the surface of the beam by image processing. The surface and active layers of the Gafchromic film have a thickness of $7.25 \mu \mathrm{m}$, ensuring that $60 \mathrm{keV}$ electrons will go through it, as shown by ESTAR simulations. ${ }^{12}$ Nevertheless, the dose range at which they are operational (maximum 500 Gy for the HD-810 film used in the present work) is not well adapted to our experimental conditions for which the dose is much higher. Noteworthy, no especially dedicated film for dosimetry exists for the $60 \mathrm{keV}$ electrons of the present experiment, making the dose determination complex. Therefore, we chose to use a Faraday cup for current measurement. The Faraday cup used is a Kimball FC-72A with an aperture size around $1 \mathrm{~cm}^{2}$. A rejection grid voltage $(+50 \mathrm{~V})$ enables the polarization of the Faraday Cup to trap backscattered electrons. An oscilloscope Tektronix TDS 7104 was used to determine, after integration, the total charge in the entire Faraday cup.

For a monoenergetic beam of electrons with a given kinetic energy, the dose $D$ (expressed in Gy, with 1 Gy $=1 \mathrm{~J} \mathrm{~kg}^{-1}$ ) is then given by

$$
D=\frac{1}{\rho} \frac{d Q}{d x} \int \dot{\varphi} d t
$$

with $\rho$ the density of the absorbing material; $\frac{d Q}{d x}$ the energy deposited per unit thickness in the material by one electron; and $\dot{\varphi}$ the fluence rate expressed in electrons per unit area.

We assume here that the energy deposited in the sample is lost from the electron beam, meaning that $\frac{d Q}{d x}$ is equal to the electron stopping power $\frac{-d E}{d x}$, the so-called LET (linear energy transfer). As proven by ESTAR simulations, ${ }^{12}$ all the electrons have deposited their energy within $50 \mu \mathrm{m}$, which leads to an

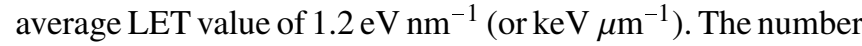
of electrons is deduced from the Faraday cup measurement and the area of the electron beam is measured on the Gafchromic film under the same conditions. For the static experiments (IR
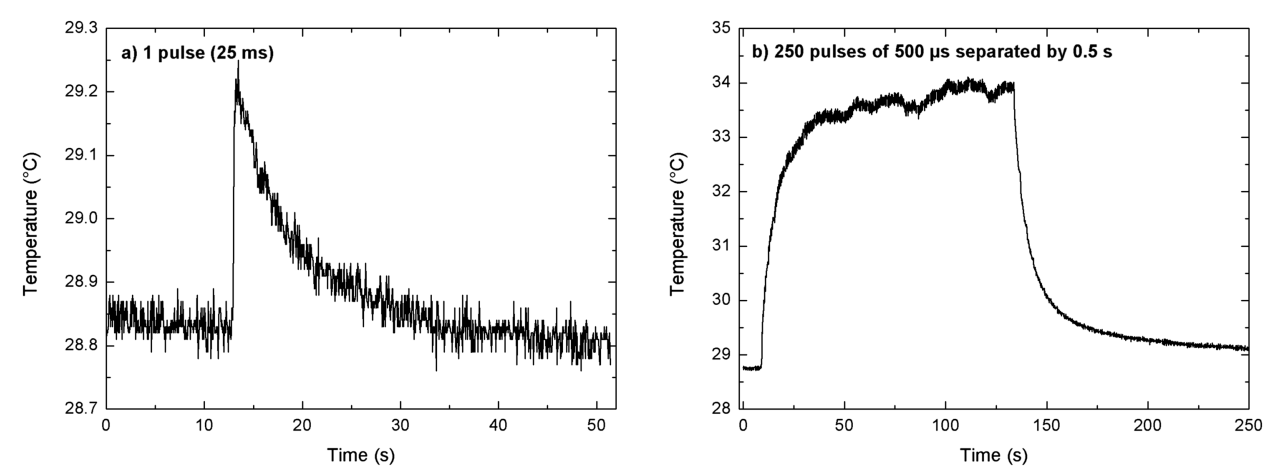

FIG. 3. Evolution of the temperature of the sample as a function of time for different irradiation conditions. The source voltage is set to $2.6 \mathrm{~V}$ and the grid value to $330 \mathrm{~V}$. On the left, a single $25 \mathrm{~ms}$ pulse induces a sample heating of about $0.4{ }^{\circ} \mathrm{C}$. On the right, 250 pulses of 500 $\mu$ s duration (all the pulses are separated by $0.5 \mathrm{~s}$ ) create a slight heating around $5{ }^{\circ} \mathrm{C}$. 

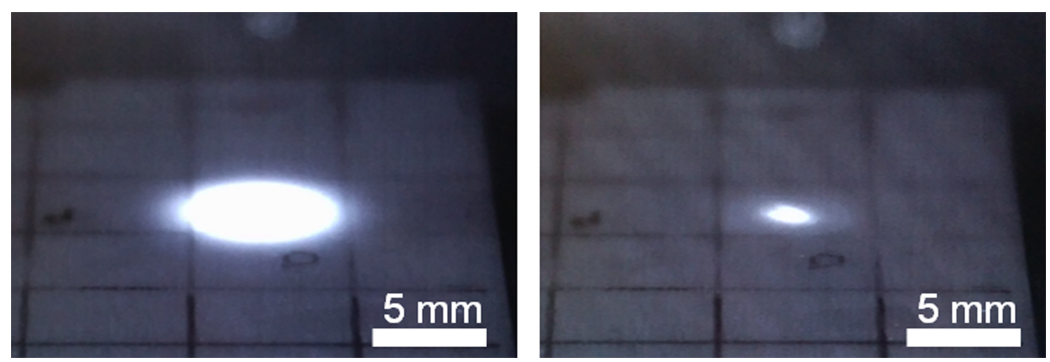

FIG. 4. Left: electron beam on chromium doped alumina. The diameter is about $6 \mathrm{~mm}$. Right: Visualization of the infrared beam in the near-infrared thanks to the near-infrared source of the FT-IR spectrometer (no electron beam). The infrared beam is smaller $(2.5 \mathrm{~mm})$ than the electron beam and is located within the electron beam.

analysis performed before and after irradiation), the dose per pulse was measured at $4000 \mathrm{~Gy}_{\text {pulse }}{ }^{-1}$ for a $0.5 \mathrm{~ms}$ pulse. Each pulse is separated from the following by $0.5 \mathrm{~s}$. The dose per pulse is very reproducible, as evidenced by regular measurements from the Faraday cup during one experiment. This means that, at given experimental conditions, the duration of the pulse enables setting the desired dose. Therefore, for the rapid scan experiments, we adjusted the pulse duration at $25 \mathrm{~ms}$ depending on the results obtained in the static mode. Under these conditions, the dose per pulse is $200 \mathrm{kGy}$.

\section{Coupling with infrared spectroscopy}

A Fourier transform infrared detection associated with the electron gun was implemented so as to characterize in situ the effects of irradiation. The InfraRed Reflection Absorption Spectroscopy (IRRAS) approach is used here. The setup including the electron gun, the experimental chamber, and the infrared beam is depicted in Figs. 1 and 2. The infrared beam from a globar source (diameter: $6 \mathrm{~mm}$ ) exits the infrared spectrometer (Bruker Vertex 70), is guided thanks to gold mirrors, and crosses an infrared-transparent window $(\mathrm{ZnSe})$ before entering the experimental chamber. It is focused on the sample with a $90^{\circ}$ off axis parabolic mirror (diameter: $12.8 \mathrm{~mm}$ ) having a reflected focal length of $50.8 \mathrm{~mm}$. The IR incidence angle is $45^{\circ}$ onto the sample. This value of the incidence angle is dictated by the mechanical arrangement of the setup. The infrared beam focus on the sample is about $2.5 \mathrm{~mm}$, which is smaller than the electron beam focus (Fig. 4). After specular reflection on the sample, the infrared light is collimated by a normal parabolic mirror (diameter: $75 \mathrm{~mm}$ ) with a $75 \mathrm{~mm}$ focal length installed off axis. It crosses a second infraredtransparent window made of $\mathrm{ZnSe}$ to be detected by an external MCT (mercury cadmium telluride) detector. The use of one parabolic mirror (instead of an off axis parabolic mirror) was dictated by questions of size and ease of adjustment. Last, the IR light arising from the parabolic mirror is collimated and then focused on the MCT detector installed on the chamber thanks to an off axis parabolic mirror integrated in the detector (Fig. 5). The total optical path is about $1.5 \mathrm{~m}$ (Figs. 1 and 5).

With this experimental setup, it is possible to record simultaneously all wavenumbers ranging from 800 to $4000 \mathrm{~cm}^{-1}$.

\section{Visualization of the electron and infrared beams}

To perform the experiments, an accurate alignment of the infrared beam is necessary. It is a crucial point, as the probe infrared beam has to be located within the electron beam. To achieve this goal, the visualization of the infrared beam is required (the electron beam being visualized thanks to chromium doped alumina). This is performed thanks to near infrared light source (tungsten halogen lamp), knowing that the optical path remains the same whatever the light source in the

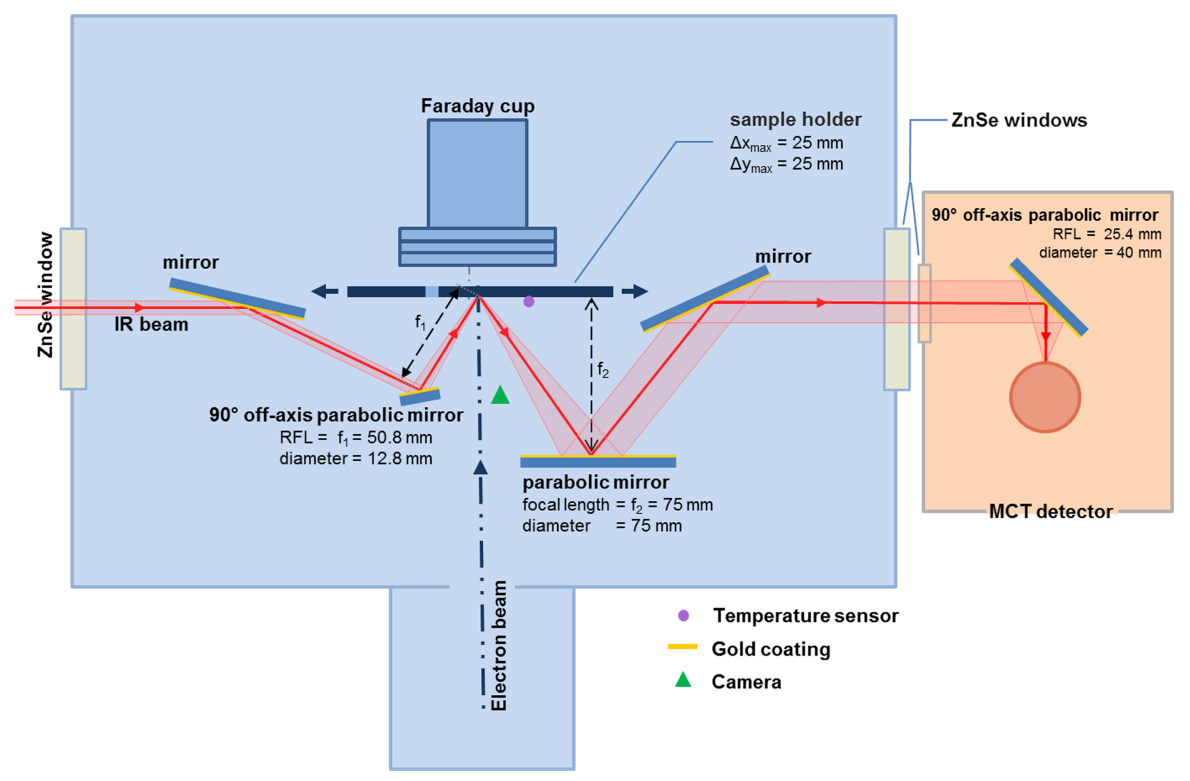

FIG. 5. A schematic illustration of the infrared optical path within the irradiation chamber and in the MCT detector. The MCT detector is installed on the chamber. 
FT-IR spectrometer. The visualization of the size and position of the electron and infrared beam (Fig. 4) is then performed thanks to a CCD camera purchased from Edmunds (CCIR Monochrome Camera) sensitive to the near infrared and which is installed in the experimental chamber (Fig. 5). The two beams can then be aligned so as to enable a good overlap between them and to ensure that the infrared probe light is comprised within the electron beam. Therefore, the effects due to electron irradiation are detected thanks to the infrared beam. Noteworthy, it is possible to focus tighter the electron beam. Nevertheless, in this case, the dose per pulse increases significantly. This can lead to a damage of the film. Therefore we chose to work with an electron beam which has a diameter of roughly $6 \mathrm{~mm}$.

\section{Static infrared experiments}

The spectra were averaged from 100 scans at a $4 \mathrm{~cm}^{-1}$ resolution. As the rapid scan mode is implemented (see below), we can benefit from the high scanning frequency $(160 \mathrm{kHz})$ to record the spectra very quickly after the electron pulse. A $\mathrm{KBr}$ beamsplitter is used. Two sources are available: the common $\mathrm{SiC}$ globar source for the experiments in the mid-infrared range, and a tungsten halogen lamp, that emits near infrared light, for the infrared beam visualization. Spectra of pristine films were recorded with respect to a $\mathrm{KBr}$ pellet present on the sample holder. Spectra of irradiated films were recorded with reference to the same film before irradiation, which enables the detection of the irradiation effects by measuring differential absorption.

\section{Rapid scan infrared experiments}

Rapid scan ${ }^{16,17}$ experiments start with the acquisition of the background before irradiation. Then the electron gun is fired to trigger the reaction. The resolution is $8 \mathrm{~cm}^{-1}$. The scanning frequency is set to its maximum value, i.e., $160 \mathrm{kHz}$. Under these experimental conditions, an interferogram is recorded in $71 \mathrm{~ms} ; 11 \mathrm{~ms}$ are then necessary to allow the mirror to get back to its initial position to start the next acquisition. Thus, interferograms are taken every $82 \mathrm{~ms}$. 128 time points are recorded. Spectra are averaged from 50 scans and are recorded on a total time of roughly $10 \mathrm{~s}$.

For all infrared experiments, the data were analyzed thanks to the OPUS software from Bruker.

\section{Sample}

The experiments were performed on thin films $(5 \mu \mathrm{m})$ of bisphenol A polycarbonate (see Fig. 6) chosen because it is an important thermoplastic polymer. However, its properties are damaged by weathering, which limits its use. Therefore, the understanding of the degradation reaction mechanisms is important, and degradation is induced here by accelerated electrons. ${ }^{18}$ This polymer was chosen to test the new setup, first because its behavior under radiation, both ionizing and nonionizing, is well documented in terms of defects creation and second because the high IR molar absorptivity of carbonate functions enables the observation of tenuous modifications on these groups. Besides, carbonate groups are the weakest sites of this polymer under irradiation. Moreover, the rapid scan

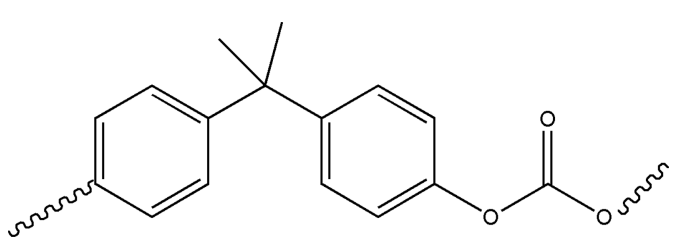

FIG. 6. Structure of bisphenol A polycarbonate.

mode will enable the investigation of $80 \mathrm{~ms}-10 \mathrm{~s}$ time scale. To increase the infrared signal, a thin gold coating of $200 \mathrm{~nm}$ was deposited thanks to the Emitech K575X turbo sputter coater at the rear of the polymer film. The same was performed on the $\mathrm{KBr}$ pellet.

\section{RESULTS AND DISCUSSION}

The infrared spectrum of the bisphenol A polycarbonate thin film is represented in Fig. 7. The infrared spectrum is the same as the one recorded in a "classical" transmission mode, proving that the recorded infrared spectra are of good quality (see Fig. S2 in the supplementary material). The assignment of the corresponding IR bands is given in Table S1 (see the supplementary material).${ }^{19}$ Due to the thickness of the film, the spectral region around $1200 \mathrm{~cm}^{-1}(\mathrm{C}-\mathrm{O}$ stretch$)$ is saturated and is not exploited.

The differential absorption spectra recorded for different irradiation doses are given in Figs. 8(a)-8(c) for the spectral regions of interest. The $1200 \mathrm{~cm}^{-1}$ spectral region could not be exploited.

The first inspection of Fig. 8 evidences the good signal to noise ratio that is achieved in all the spectra except in the 3000$4000 \mathrm{~cm}^{-1}$ range which are much noisier due to a reduced intensity of the IR beam (Fig. 8(c)). Nevertheless, it is also clear from Fig. 8(c) that differential absorbances as low as $1 \mathrm{mOD}$ are detectable and can then be interpreted. Our in situ experiment offers then a significant benefit in terms of sensitivity (but not in terms of spectral resolution) as compared to ex situ experiments. Modifications of a few percent of initial bands

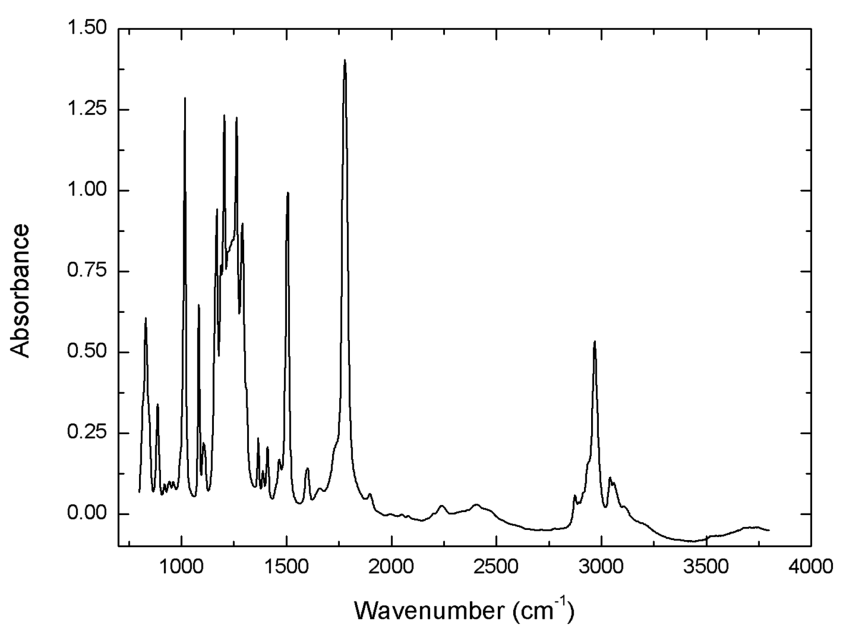

FIG. 7. Infrared spectrum of a $5 \mu \mathrm{m}$ thick bisphenol A polycarbonate film obtained with the ACCIR platform. 

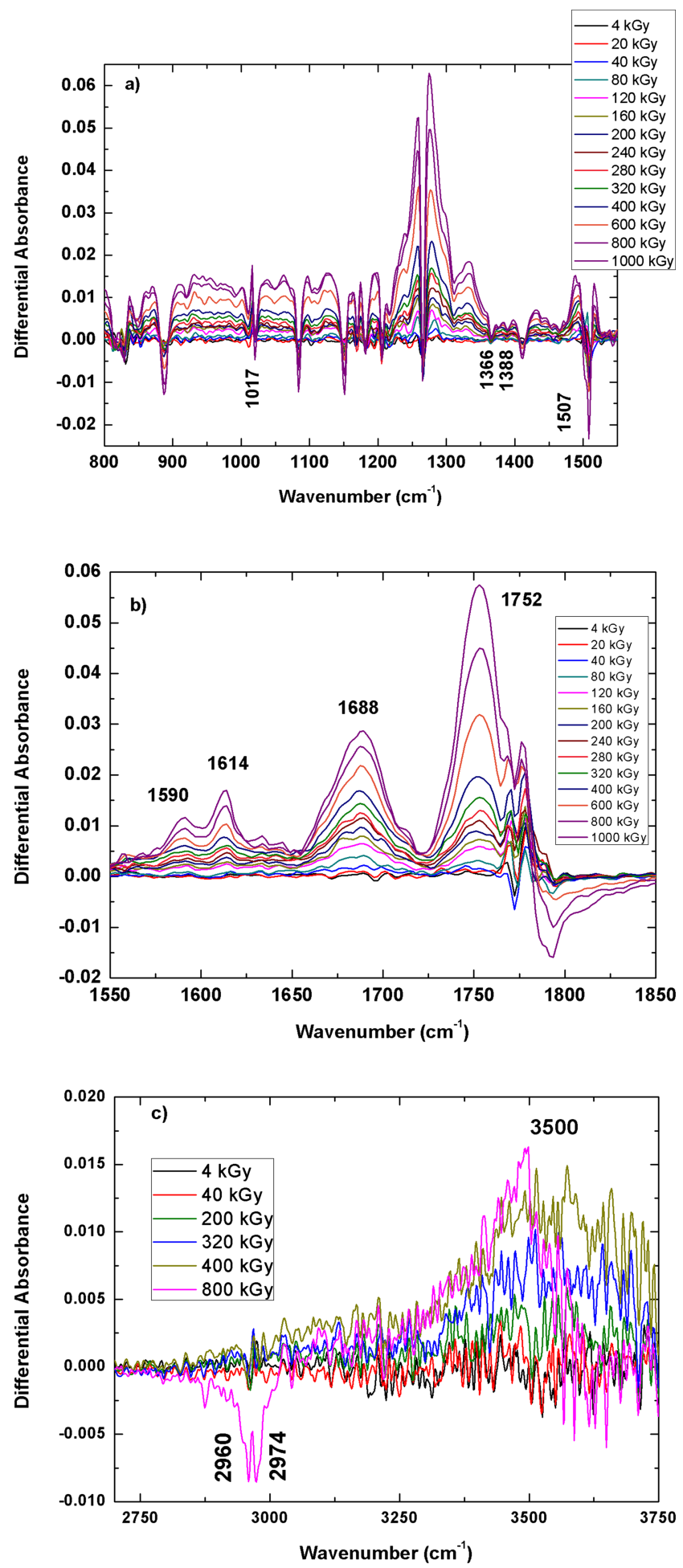

FIG. 8. (a)-(c). Differential absorbances measured at different doses in the spectral regions of interest. The pulse duration is $0.5 \mathrm{~ms}$ and the pulses are separated by $0.5 \mathrm{~s}$. In Fig. $8(\mathrm{a})$, the vibrations around $1200 \mathrm{~cm}^{-1}$ cannot be analyzed due to the saturation of this signal in the pristine film. A positive absorbance corresponds to either the creation of new bonds or the modification of the chemical environment of native bonds; a negative one to bonds that are cleaved or whose environment is modified. The characteristic wavenumbers of the main bands cited in the text are indicated.

are clearly seen (Fig. 8(a)). For instance, the $\mathrm{O}-\mathrm{H}$ stretching mode around $3500 \mathrm{~cm}^{-1}$ is observed (Fig. 8(c)), which would have been much more tricky with an ex situ experiment.
In Fig. 8(a), the decrease of the absorbance related to the vibration modes of the benzene ring is clearly depicted from the first irradiation pulse. The modifications on the $-\mathrm{CH}_{3}$ groups (bands at 1366 and $1388 \mathrm{~cm}^{-1}$ ) are minor as compared to the modification of the aromatic ring (bands at $1507 \mathrm{~cm}^{-1}$ ) (Fig. 8(a)). Therefore, no modification on the methyl groups will be discussed in Fig. 9 below, which is also consistent with previous studies. ${ }^{20}$ The most striking feature is depicted in Fig. 8(b). It is clear here that the $\mathrm{C}=\mathrm{O}$ band of the carbonate unit is affected by accelerated electrons from the lowest dose. New features appear at 1752, 1688, 1614, and $1590 \mathrm{~cm}^{-1}$. The band at $1752 \mathrm{~cm}^{-1}$ was previously attributed to the carbonyl stretching vibration in carbonate units inter- or intra-molecularly hydrogen bonded with hydroxyl groups. ${ }^{18}$ The band around $1688 \mathrm{~cm}^{-1}$ was attributed to carbonyl stretching vibration in phenylsalicylate compounds that are formed upon irradiation (Fig. 8(b)). ${ }^{18}$ The other bands located at 1614 and $1590 \mathrm{~cm}^{-1}$ were, respectively, assigned to quadrant stretching of ring $\mathrm{C}=\mathrm{C}$ bonds in hydroxyl substituted ring and in carbonyl substituted ring. ${ }^{20}$ The $2700-4000 \mathrm{~cm}^{-1}$ spectral range is much noisier (Fig. 8(c)). Hence, we choose not to display all spectra in this wavenumber range. Nevertheless, it is clear that no modification is observed at the lowest number of pulses. When the irradiation dose increases, the negative signal around $2960 \mathrm{~cm}^{-1}$ indicates that the $-\mathrm{CH}_{3}$ groups are affected by the reactions taking place under electron irradiation. Moreover, the $\mathrm{O}-\mathrm{H}$ stretching band presents a positive differential absorbance with a maximum centered around $3525 \mathrm{~cm}^{-1}$ that was assigned to $\mathrm{OH}$ stretching of free hydroxyl in phenol units, ${ }^{20}$ whereas the component around $3200 \mathrm{~cm}^{-1}$ is assigned to intramolecularly hydrogen bonded $-\mathrm{OH}$ groups in phenol units. All together, the spectra we measure here are in line with previous studies dealing with the modifications of this polymer induced by swift heavy ions ${ }^{18}$ and also with photodegradation studies. ${ }^{20}$

From these spectra, the major degradation pathways that can be proposed are given in Fig. 9.

As described in Sec. II, rapid scan experiments were also performed with a time resolution of $82 \mathrm{~ms}$. In this case, a $25 \mathrm{~ms}$ electron pulse was used. Two kinetic curves are given in Fig. 10. More accumulations would increase the signal to noise ratio, but the features depicted in Fig. 10 are clear enough to be discussed. At $1510 \mathrm{~cm}^{-1}$, the signal is negative and corresponds to modifications in the aromatic ring. Simultaneously, a positive signal due to a peak shift is detected at $1489 \mathrm{~cm}^{-1}$. These two features can be associated with the same type of vibrations, namely, the ring semicircle stretching mixed with $\mathrm{C}-\mathrm{H}$ bending, linked with either the modifications in the type of substituents on the ring or the change in the substitution degree of the ring. The formation of carbonate hydrogen bonded with hydroxyl groups is followed through the carbonyl stretching vibration at $1752 \mathrm{~cm}^{-1}$ (Fig. 10). In all cases, with this $25 \mathrm{~ms}$ electron irradiation, the signals detected just after the irradiation pulse decay quickly to give a signal that is stable a few seconds after irradiation. The time-resolved spectra recorded in the $\mathrm{C}=\mathrm{O}$ stretching region are very complex and evolve with time (Fig. 10). The component at $1752 \mathrm{~cm}^{-1}$ decays to give less complex signal that is centered around $1779 \mathrm{~cm}^{-1}$, (Fig. 10, inset top right), that corresponds to the 


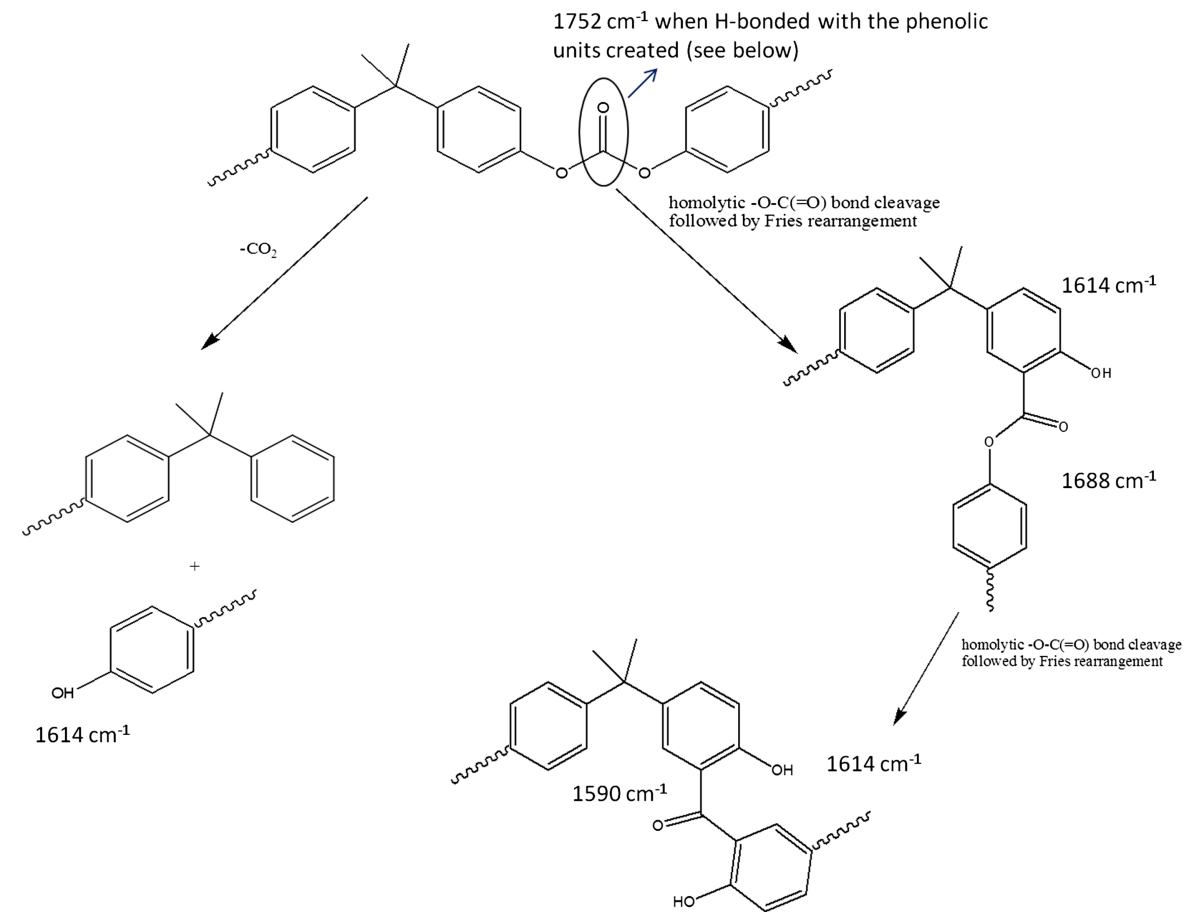

FIG. 9. A schematic illustration of the reaction mechanisms of bisphenol A polycarbonate evidenced by infrared spectroscopy. The characteristic wavenumbers are indicated near the new chemical functions created.

wavenumber of the initial compound. We notice here that the differential absorbance measured at the longest times for a $200 \mathrm{kGy}$ dose is weaker than the corresponding absorbance (for the same dose) in the static experiments (Figs. 8(a) and 8(b)). Therefore, we assume that with this high-dose pulse, the density of created species is very high, favoring their recombination into the parent species due to cage effect. The times we measure here for these recombination reactions (few hundreds of ms) are consistent with the ones that are reported in solid polymers. ${ }^{21}$ It is therefore not equivalent to work with a $25 \mathrm{~ms}$ pulse or to submit the sample to 50 electron pulses of $0.5 \mathrm{~ms}$, even if the total dose is the same. At $1510 \mathrm{~cm}^{-1}$, a peak shift is observed (Fig. 10, spectra at the bottom) and the intensity

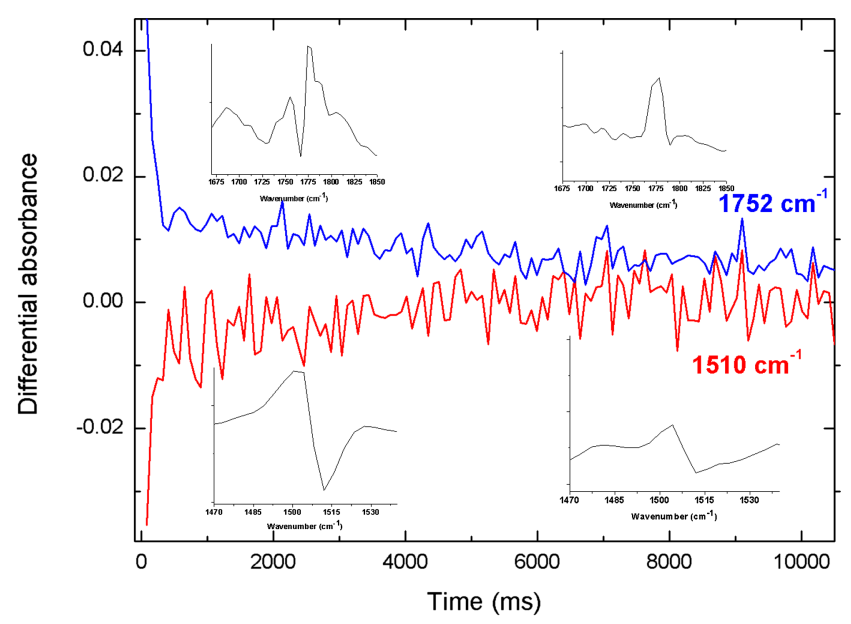

FIG. 10. Evolution of the differential absorbance as a function of time (time resolution: $82 \mathrm{~ms}$ ) for two wavenumbers: $1510 \mathrm{~cm}^{-1}$ (red) and $1752 \mathrm{~cm}^{-1}$ (blue). Differential spectra recorded at short (left) and longer times (right) are also given. of the peaks decays with time, for the same reasons as stated above.

\section{CONCLUSION}

We have presented here our new experimental platform that couples an infrared detection arising from a commercial infrared spectrometer, making the $800-4000 \mathrm{~cm}^{-1}$ wavenumber range directly available with a $60 \mathrm{keV}$ pulsed electron gun. It delivers electrons that will penetrate $50 \mu \mathrm{m}$ in the sample, which is of the same order of magnitude as the optical paths in infrared spectroscopy (a few $\mu \mathrm{m}$ ). First experiments were performed on thin films (with a thickness of a few $\mu \mathrm{ms}$ ) and results were obtained in the static mode as well as with rapid scan that provides an $80 \mathrm{~ms}$ time resolution giving access to ms-s kinetics. Therefore, the degradation of polymers, and more generally, reaction mechanisms induced by ionizing radiation, can be studied in situ and in real time, which allows proposing reaction mechanisms.

The next development includes the implementation within the experimental chamber of a liquid cell with very thin optically transparent windows (200 $\mathrm{nm})$ and working under high vacuum conditions in a flowing mode. As the electron gun has a pulsed structure, with a time resolution down to $2 \mu \mathrm{s}$, it will then be possible to perform experiments using the step scan mode ${ }^{17,22}$ with a time resolution of a few $\mu$ s. These new developments will be of great interest to follow the reactivity induced by electrons at these time scales $(>\mu \mathrm{s})$, allowing determining reaction mechanisms in various important fields such as electrochemistry, biochemistry, polymerization, and degradation of polymers. Last, this timescale will usefully complement the one available at Brookhaven National Laboratory (ns- $\mu \mathrm{s})$. 


\section{SUPPLEMENTARY MATERIAL}

See supplementary material for the evolution of the voltage vs. time on the Faraday cup, for the comparison between infrared spectra recorded in transmission mode and with the ACCIR platform, and for the assignment of the main IR bands of bisphenol A polycarbonate.

\section{ACKNOWLEDGMENTS}

This work was supported by the French National Research Agency (ANR) under the "SPIRIT" project and by C'Nano Ile-de-France. Bruker (Gregory Candor) is gratefully acknowledged for discussion and help. We thank Dr. Emmanuel Balanzat for the chromium doped alumina. Last, Dr. Stanislas Pommeret is gratefully acknowledged for fruitful discussion.

${ }^{1}$ J. R. Schoonover and G. F. Strouse, "Time-resolved vibrational spectroscopy of electronically excited inorganic complexes in solution," Chem. Rev. 98, 1335-1356 (1998).

${ }^{2}$ M. H. Moore, B. Donn, R. Khanna, and M. F. A'Hearn, "Studies of protonirradiated cometary-type ice mixtures,” Icarus 54, 388-405 (1983).

${ }^{3}$ J. Benit, J.-P. Bibring, and F. Rocard, "Chemical irradiation effects in ices," Nucl. Instrum. Methods Phys. Res., Sect. B 32, 349-353 (1988).

${ }^{4}$ N. Betz, A. Le Moël, E. Balanzat, J. M. Ramillon, J. Lamotte, J. P. Gallas, and G. Jaskierowicz, "A FTIR study of PVDF irradiated by means of swift heavy ions,” J. Polym. Sci., Part B: Polym. Phys. 32, 1493-1502 (1994).

${ }^{5}$ E. Balanzat, N. Betz, and S. Bouffard, "Swift heavy ion modification of polymers," Nucl. Instrum. Methods Phys. Res., Sect. B 105, 46-54 (1995).

${ }^{6}$ M. Mascioni, J. M. Sands, and G. R. Palmese, "Real time in situ spectroscopic characterization of radiation induced cationic polymerization of glycidyl ethers," Nucl. Instrum. Methods Phys. Res., Sect. B 208, 353-357 (2003).

${ }^{7}$ S. Le Caër, G. Vigneron, J. P. Renault, and S. Pommeret, "First coupling between a LINAC and FT-IR spectroscopy: The aqueous ferrocyanide system," Chem. Phys. Lett. 426, 71-76 (2006).

${ }^{8}$ S. Le Caër, G. Vigneron, J. P. Renault, and S. Pommeret, "Radiolysis of ferrocyanide solutions studied by infrared spectroscopy," Radiat. Phys. Chem. 76, 1280-1284 (2007).
${ }^{9}$ D. C. Grills, A. R. Cook, E. Fujita, M. W. George, J. M. Preses, and J. F. Wishart, "Application of external-cavity quantum cascade infrared lasers to nanosecond time-resolved infrared spectroscopy of condensedphase samples following pulse radiolysis," Appl. Spectrosc. 64, 563-570 (2010).

${ }^{10}$ D. C. Grills, J. A. Farrington, B. H. Layne, S. V. Lymar, B. A. Mello, J. M. Preses, and J. F. Wishart, "Mechanism of the formation of a Mn-based $\mathrm{CO}_{2}$ reduction catalyst revealed by pulse radiolysis with time-resolved infrared detection," J. Am. Chem. Soc. 136, 5563-5566 (2014).

${ }^{11}$ D. C. Grills, J. A. Farrington, B. H. Layne, J. M. Preses, H. J. Bernstein, and J. F. Wishart, "Development of nanosecond time-resolved infrared detection at the LEAF pulse radiolysis facility,” Rev. Sci. Instrum. 86, 044102 (2015).

${ }^{12}$ M. J. Berger, J. S. Coursey, M. A. Zucker, and J. Chang, 1.2.3 ed, National Institute of Standards and Technology, Gaithersburg, MD, http//physics.nist.gov/Star, 2005.

${ }^{13}$ Z. Cai, X. Pan, D. Hunting, P. Cloutier, R. Lemay, and L. Sanche, "Dosimetry of ultrasoft $\mathrm{X}$-rays $\left(1.5 \mathrm{keV} \mathrm{Al}_{\mathrm{K} \alpha}\right)$ using radiochromatic films and colour scanners," Phys. Med. Biol. 48, 4111-4124 (2003).

${ }^{14}$ S. D. Sharma, R. H. Chilkulwar, and R. Kumar, "Dosimetry during mango irradiation using Gafchromic HD-810 film," Radiat. Prot. Dosim. 133, 208213 (2009).

${ }^{15} \mathrm{~S}$. Yencho and D. R. Walz, "A high-resolution phosphor screen beam profile monitor,” IEEE Trans. Nucl. Sci. 32, 2009-2011 (1985).

${ }^{16}$ P. R. Griffiths, C. T. Foskett, and R. Curbelo, "Rapid scan infrared Fourier transform spectroscopy," Appl. Spectrosc. Rev. 6, 31-77 (1972).

${ }^{17}$ P. R. Griffiths and J. A. De Haseth, Fourier Transform Infrared Spectrometry (John Wiley and Sons, 2007).

${ }^{18}$ F. Dehaye, E. Balanzat, E. Ferain, and R. Legras, "Chemical modifications induced in bisphenol a polycarbonate by swift heavy ions," Nucl. Instrum. Methods Phys. Res., Sect. B 209, 103-112 (2003).

${ }^{19}$ N. B. Colthup, L. H. Daly, and S. E. Wiberley, Introduction to Infrared and Raman Spectroscopy, 3rd ed. (Academic Press, San Diego, 1990).

${ }^{20}$ A. Rivaton, "Recent advances in bisphenol-A polycarbonate photodegradation," Polym. Degrad. Stab. 49, 163-179 (1995).

${ }^{21}$ L.-P. Hwang and J.-T. Cheng, "Cage effects in recombination of allyl radicals in irradiated polyethylene,” J. Polym. Sci., Polym. Phys. Ed. 19, 983-989 (1981).

${ }^{22}$ W. Uhmann, A. Becker, C. Taran, and F. Siebert, "Time-resolved FT-IR absorption spectroscopy using a step-scan interferometer," Appl. Spectrosc. 45, 390-397 (1991). 